\title{
Web-based health databases and real-time GIS-based disease surveillance for leprosy control: fighting ancient evil with modern tools
}

\author{
Millawage Supun Dilara Wijesinghe \\ Anti-Leprosy Campaign, Ministry of Health, Sri Lanka \\ Correspondence: dr.wijesinghe@gmail.com (D) https://orcid.org/0000-0001-8417-0098 \\ DOI: https://doi.org/10.4038/jccpsl.v24i2.8152
}

Received on: 19 April 2018

Accepted on: 21 May 2018

\section{Introduction}

Leprosy is a chronic infectious disease that affects the skin and peripheral nerves of the body. This condition results from an obligatory intracellular bacteria called Mycobacterium leprae. It has a very long incubation period (on average 3-5 years) (1). The global caseload of leprosy had decreased following the introduction of multi-drug therapy in the world. However, the South East Asia Region is still struggling to get the disease under control, with over $70 \%$ of the global burden reported from this zone (1). Over the past decade, Sri Lanka has recorded close to 2000 cases per year. This figure is equal to an annual new case detection rate of 8-10 per 100,000 population. The prevalence of child cases (8-10\%) and grade 2 deformities (7-10\%) is still a significant public health concern in the country, signifying persistent transmission of the disease in the community and late detection of cases (2).

Over the years, leprosy control programmes have used many trial preventive strategies to forestall transmission of leprosy in the community. These include vaccines, immunoassays (for early screening) and chemoprophylaxis. However, none of these was able to stop the transmission in the population in many endemic countries (3). The only practical strategy so far in preventing transmission has been the active case finding and early treatment (3). This situation is more or less the same in Sri Lanka as well.

In Sri Lanka, one of the significant barriers to active case finding is the non-availability of instant access to accurate individual-level patient data for the district and central programme managers (4). This barrier is imputable to the fact that patients are diagnosed through a passive system via the dermatology clinics. Furthermore, transmission of this data to the field level for active case finding is not timely and sometimes inadequate. Despite many active case finding surveys conducted at the district level, the follow-up of suspected cases remains a problem. This issue in the linkage is due to lack of data flow from the dermatology clinics to the districts. Furthermore, linking of data of the dermatology clinics and district teams is inadequate and delayed, leading to many problems in conducting control activities at the field level. The other significant challenge in planning control activities is non-availability of exact locations of the patients, which in-turn hinders the focused screening activities such as community surveys and house to house surveys (4). The lack of targeted screening leads to waste of resources and low yield making these activities almost ineffective. Both these shortcomings can be overcome by having a web-based health database and a real-time geographical information system (GIS)-based disease surveillance system. Such a system will prevent the delay of screening activities by timely sharing the data from the dermatology clinics with the district teams, and strengthen the focused control activities making health care financing more productive.

\section{Methods}

\section{Web-based health databases in leprosy control}

A web-based database is a database system that is developed for data to be accessed and maintained 
via the internet. This system is dissimilar to the preceding era's databases where the database is kept on a single machine or a network. In this type of a system, the data entry and maintenance need to be executed at the same physical location (5). With the evolution of internet technologies, the popularity of web-based systems has grown over the past two decades. Upon recognition of the advantages of these systems, the health sector in many developed countries was quick to adopt web-based database systems. However, the developing countries are still not using web-based database systems to their fullest potential. Sri Lanka is no exception in this regard (6). Nonetheless, this trend has changed over the past few years. With the late developments in information technology in the field of public health, many are now integrating web-based health databases into their conventional systems.

The simplest web-based health database architecture includes the following essential components (5):

1. Web browser/Mobile App (interface connecting the user via the internet to the database)

2. Web server (component receiving the request from the browser)

3. An application server (help the execution of programmes, security of the system and web session management)

4. Software application (interfaces with an application server to provide output web pages)

5. Database software (interfaces with an application server to provide the data needed)

The developers at Anti-Leprosy Campaign (ALC) used this software architecture in developing the modern leprosy web-based health database (LeIS) (Figure 1). The public health inspectors of leprosy control (LC-PHI) were selected as points of data entry in this system. ALC provided them with a tablet computer based on an Android operating system for this function. The developers designed the database to deliver the primary interface through a web browser where the LC-PHI enters the data of individuals diagnosed of having leprosy into the scheme. The database software used in this system was MySQL, and the developers designed the 'application user interface' using Myphp. They built up the 'dashboard user interface' in such a way that district programme managers of the district teams were able to see the high-endemic areas in their districts and key performance indicators (child percentage, multibacillary percentage, and grade 2 disability) at a glance. At ALC, the present database system has been functioning for two successive years. In this system, LC-PHIs collected $99 \%$ of the data from dermatology clinics and transmitted to the teams in relevant districts. This system provides accurate real-time data for the 25 programme managers for decision making in planning control measures in their regions. The programme managers at district level use this system as a visual aid in planning service provision (via satellite clinics) for leprosy patients in the districts.

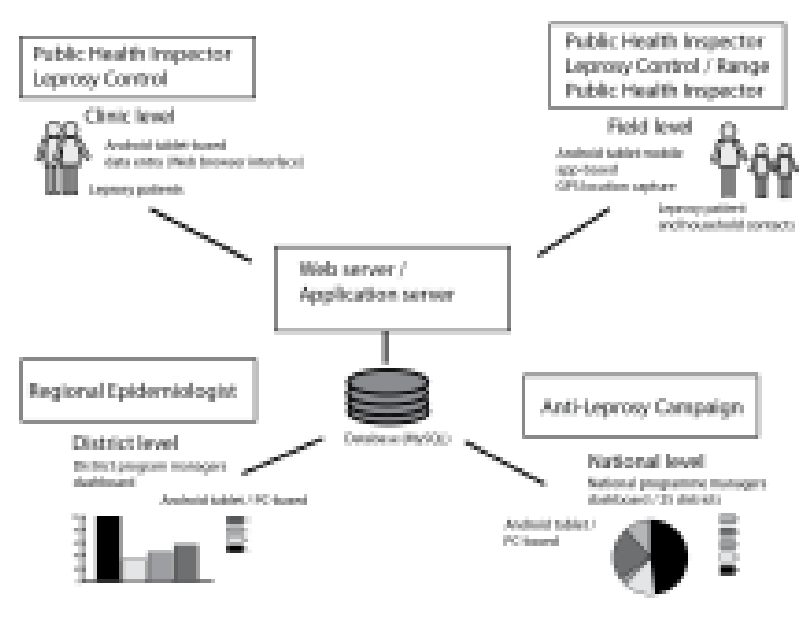

Figure 1. Software architecture diagram of the ALC system

\section{Real-time GIS-based disease surveillance}

Mapping an infectious disease has many significant public health benefits. It increases the ability of identifying the spread and transmission of the infective agent, thereby helping the decision-making process of selecting a suitable control measure in prevention. It also aids as a visualisation tool in conveying the risk and progress of the preventive actions. GIS-based disease surveillance has many advantages over the traditional systems such as it can detect clustering of events (that aggregated tabular data usually tends to overlook), identification of social and environmental factors that influence disease transmission, and revealing trends, dependencies and inter-relationships which is obscure (7-8). The key areas that programme managers in leprosy control can use GIS include: carrying out focused screening strategies (community- 
based surveys and house-to-house surveys), monitoring and evaluation activities, advocacy, predicting time trends and research (to bring forth new insights in disease transmission) (9).

The World Health Organization (WHO) framework for building up a GIS system for leprosy elimination describes the following key components in their approach. Accurate location of each treatment facility of a country, developing a base map from available data sources and entering the relevant attributes of the location points into a GIS database system (8). These key components can be developed from the four essential elements such as machine hardware, software, data and 'liveware' (10). The first two components are now available either as proprietary things or open source systems. The third element is much more crucial and expensive to collect and the cost to collect data usually exceeds the first two elements. The 'liveware' element indicates the personnel involved in implementing the GIS system. The personnel of a GIS system can range from people who are collecting the locations (and attributes) to those who are analysing and producing the desired maps and reports (11). The developers at ALC developed the present GIS system based on the framework above. Similar to the webbased database, the LC-PHI was the key 'livewire' element. Since the health institution layer and all its attributes were already available for Sri Lanka, mapping of the physical locations of patients was the major resource intense activity in developing the GIS-based system. This challenge in mapping the locations will be overcome by introducing an Android app interface with a link to the web-based health database. The LCPHIs visited the households of leprosy patients and collected location-based information. ALC supplied a dedicated data sim card to the Android tablet they are using for data entering. Since the locations were obtained based on the PHI areas, all the range PHI areas were hard-coded and entered into the health database. This system provided real-time data of individual patients in each PHI area. Thus, the district programme managers were able to identify clustering of cases and regions that needed focused interventions. With this system, they were able to plan leprosy screening programmes in districts up to the street level instead of Grama Niladhari (GN) and village levels. This identification of clustering of cases promoted proper use of resources which is vital to countries like Sri Lanka where financial and human resources are scarce.

\section{Discussion and Conclusions}

Many policymakers in the developing countries have not recognised the added value of GIS. The policymakers categorise it as a superfluous (costly) activity and tend to avoid funding these systems (12). This situation was relevant to Sri Lanka as well. To overcome this criticism, critical public health gatekeepers have been advocated in the Ministry of Health about the additional advantage the GIS brings to the disease surveillance process. Further, the traditional government funding mechanisms are not sufficient for implementing innovations in public health. This deficiency was overcome by employing much more flexible external grant-based funding mechanisms, which are more effective in this kind of situation.

Other key challenges faced include: lack of proper policies and procedures, unskilled workforces, and expensive hardware and software required to modernise the system which is also reported in related literature (13). Similar to many other countries, a few years ago the leprosy health information system of Sri Lanka was paper-based and lacked individual level patient data at the central level. The challenge of modernising the paper-based system to a web-based system was overcome by developing the new system in a stepwise manner according to a modular format. It provided the necessary time for the workforce to adapt to the new system and the essential step-wise funding process which satisfy most of the external grant-based funding mechanisms.

The infrastructure demands to install the webbased system at the beginning are usually very costly. It requires purchasing new equipment and providing data services to the healthcare providers. During implementation of the present system, many difficulties have arisen in selecting a data service, since the provision of data services based on the cost alone was not satisfactory. This dilemma is imputable to the fact that in some rural areas, the coverage of the cheapest data services is not enough compared to more expensive providers. Similar situations have been reported in many other countries $(6,12-14)$. The only alternative to this at present is to introduce a system that is capable of saving data and coordinates offline, which can be later exported to the central database.

Change management and training the staff to adopt the new system can be a daunting task for many 
programme managers with the seasoned team lacking the skills on capturing essential aspects of the webdatabase and real-time GIS-based disease mapping. If the change management is not handled, some of them will tend to oppose the change and it will bear upon the sustainability of the whole system $(12,14)$.

\section{References}

1. Nunzi E \& Massone C. Leprosy: a Practical Guide. Styria: Springer, 2012.

2. Anti-Leprosy Campaign. Annual Report 2016. Colombo: Ministry of Health, 2017.

3. Bratschi MW, Steinmann P, Wickenden A, Gillis TP. Current knowledge on Mycobacterium leprae transmission: a systematic literature review. Leprosy Review 2015; 86(2): 142-155.

4. Anti-Leprosy Campaign. National Leprosy Strategy 2016-2020. Colombo: Ministry of Health, 2016.

5. Elmasri R. Fundamentals of Database Systems (6 ${ }^{\text {th }}$ edition). Pearson Education India, 2008.

6. Tomasi E, Facchini LA, Maia M de FS. Health information technology in primary health care in developing countries: a literature review. Bulletin of the World Health Organization 2004; 82(11): 867-874.

7. Phillips DA, Ferreira JA, Ansah D, Teixeira HSA,
Kitron U, de Filippis T, et al. A tale of two neglected tropical infections: Using GIS to assess the spatial and temporal overlap of schistosomiasis and leprosy in a region of Minas Gerais, Brazil. Memórias do Instituto Oswaldo Cruz 2017; 112(4): 275-280.

8. WHO. Leprosy elimination - geographic information systems - monitoring and evaluation. Geneva: World Health Organization, 2017.

Available from: www.who.int/lep/monitor/gis/en/.

9. Bakker MI, Scheelbeek PFD, Van Beers SM. The use of GIS in leprosy control. Leprosy Review 2009; 80: 327-331.

10. Maguire D, Goodchild MF, Rhind DW. Geographical information systems: principles and applications. Essex: Longman Group UK, 1991.

11. McLafferty SL. GIS and health care. Annual Review of Public Health 2003; 24(1): 25-42.

12. Sipe NG \& Dale P. Challenges in using geographic information systems (GIS) to understand and control malaria in Indonesia. Malaria Journal 2003; 2: 1-8.

13. Fletcher-Lartey SM \& Caprarelli G. Application of GIS technology in public health: Successes and challenges. Parasitology 2016; 143(4): 401-415.

14. Jha MK \& Chowdary VM. Challenges of using remote sensing and GIS in developing nations. Hydrogeology Journal 2007; 15(1): 197-200. 